\title{
Ethics, Memory, Architecture (Memory-Works)
}

\author{
JULIAN BONDER \\ Roger Williams University
}

"The Act of Remembering is of the Present and its reference is in the past and thus absent"

-Andreas Huyssen ${ }^{1}$

"Society is the miracle of moving out of oneself"

-Emmanuel Levinas ${ }^{2}$

Few words have been so ubiquitous in contemporary culture as the word "memory." Since the 1980s the--perhaps obsessive-- pursuit of memory has become omnipresent. Memory, in its many forms, has become a key marker in such diverse fields as historiography, psychoanalysis, visual and performative arts, politics, information technology and the media, impacting as well, and quite significantly, the conception, creation, perception and uses of architectures, landscapes, public art and public space.

The pursuit of memory is present in the way real pasts and mythic pasts are re-presented, remembered and forgotten. Perhaps, as Andreas Huyssen suggests, "the obsessive pursuit of memory may be an indication that our thinking and living temporality are undergoing a significant shift, as modernity brought about a real compression of time and space yet also expanded horizons of time and space beyond the local" .$^{3}$ In a not so distant past, the discourse of history was there to guarantee the relative stability of the past in its pastness. Built space represented material traces of the historical past in the present and history was the background of modernity. Huyssen again, "today we think of the past as memory without borders rather that national history within border, today memory is understood as a mode of re-presentation and as belonging to the present". ${ }^{4}$

Even though monuments and memorials have been built around the globe for many centuries, the atrocities, crimes and disasters of the recent past have been self-consciously inscribed into our build environment as never before in history. Memorials in such diverse locations as Washington D.C. and Berlin, Buenos Aires and Minsk, Goree and Nantes, Liverpool and Santiago, New York and Barcelona, remind passer-byes of wars, genocides and crimes against humanity. Few cities in Europe, South America or the United States do without public spaces dedicated to some such commemoration, and the nearly instinctual response of public authorities, and communities, to public debates on such diverse issues as the "desaparecidos," the holocaust, recent wars, civil rights and slavery is to erect some kind of physical marker of that perhaps uncomfortable history. As a result, architects and artists find themselves playing an important role in public discourses about history and memory .

Projects, landscapes and buildings, serve to frame human experience, and at the same time, are catalysts for the process of memory. While we-architects ${ }^{5}$ and artists-imagine projects and embark on journeys that leave traces over the skin of the earth, our work often lies in unveiling, unearthing, uncovering as well as anchoring histories and memories in and onto territories, sites and cities. The architect's historical role has been to create a theater for actions and of memory capable of embodying truths that make it possible to affirm life and contemplate a better future. It is in the face of catastrophes, historic traumas, and human injustices that the architect's and artist's public roles becomes increasingly complex, problematic but (we hope) also necessary. So, how do we understand the critical significance of design, art, architecture and action in the public sphere upon conceiving and creating memorial spaces and democratic public spaces? How can we contribute to elaborate the ethical implications of Arendt's description of the public sphere, and by extension the democratic public space, as "the space of appearance," in the widest sense of the word? How do we position ourselves as architects, artists, teachers, and students, when working on such projects?

\section{MEMORY-WORKS: MONUMENTS, MEMORIALS}

Remembering, as a vital activity, shapes our relation with the past and defines our present and future. Memory is selective. Both personal and societal memories are always subject to construction, repression, denial. They are slippery, imperfect, impermanent, textured, unstable, and subject to distortions. A memorial's historic destiny is to preserve the memory of the past and provide conditions for new responses to and in the present. Memorial, memento, monument, like "monitor," suggest not only commemoration, but also to be aware, to mind and remind, warn, advise, and to call for action. As our political and ethical companions, memorials should function as environments for thinking about the past and the present, fostering the appearance of new critical consciousness in our democratic public domain. 


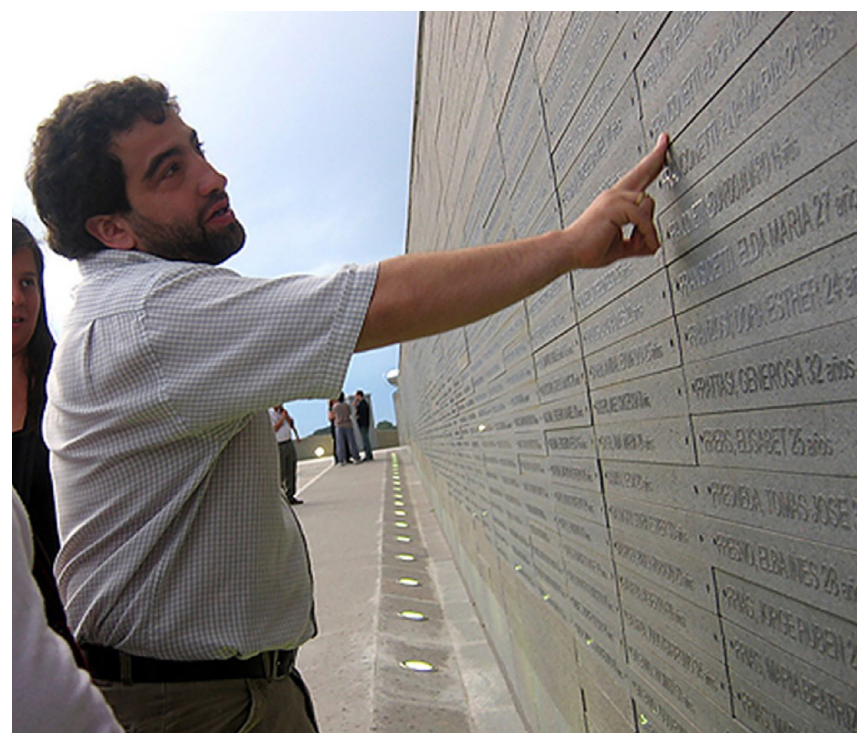

Figure 1: Parque de la Memoria - Buenos Aires.

The construction of memorials and museums all over the globe seems significant in the sheer vastness and magnitude of their number, as well as in the significance that these sites of memory may have in, and for, affected communities. Examples of this are the creation of official and community based memorial spaces, the emergence of spontaneous memorials, pilgrimages to sites of memory, and many other forms of commemorative practices. Even though the 'culture of memory' has spread over the globe, and memory's political uses are varied, at their core, these remain tied to the histories of specific communities, nations and states. An important aspect of the culture of memory may be found in the way the struggle for justice and human rights and the remembrance of traumatic events have been strongly linked to one another, as many nations-Germany, Chile, Spain, United States, Mexico, Rwanda, South Africa, Argentina (figure 1), Colombia, Guatemala, Perú among so many others--seek to create democratic societies in the wake of histories of mass exterminations, slavery, apartheids, segregation, military dictatorships, and totalitarianism. While residues of mythical meta-narratives, histories of victors, and self-aggrandizing monuments, which served in the nineteenth and twentieth centuries to "legitimize" ideologies and nation-states, may still be present in our societies, the cultures to which they speak have become "infiltrated" by "repressed" local or group memories; they have been subverted by "forgotten" micro-histories, by the appearance of the "vanquished others," those who bear witness to personal and historic traumas, those who seek to interrupt normative public narratives, those who seek to transform official monuments into what we could envision as the monument "other" (including their removal from public space).

The Latin word monumentum derives from the verb moneo, "to warn," and thus signifies "something that serves to warn, or remind with regard to conduct of future events". The word memorial, in turn, refers to "memento," that is, a thing - or more precisely a command - to mind and remind. Instead of a form, a shape, or an image, monumentality may well be a quality: the quality that some places or objects have to make us recall, evoke, think, and perceive something beyond themselves. As a place of memory-work and common remembrance, a monument or memorial is produced to be historically referential. ${ }^{6}$ Memorials can also function as mourning sites, as it is often the case where and when the traces of catastrophe are present or where and when tombstones are absent. As embodiments of memory through art in the public realm, their value is not only based or derived from the artwork, but from their ability to direct attention to larger issues; a certain point beyond themselves. Their significance lies in the public dimension and the "dialogic character of memorial space," as James Young has aptly noted - the space between the stories told, or the events remembered, and the act of remembrance (memory-work) they help frame. Time is the matter, as it is in the capacity of establishing dialogues with, and presenting questions about the past (and the future), that we find a memorial's and a monument's ethical function.

To work-through the conception and design of memorial spaces and democratic public spaces requires a persistent attempt to work within and to transform the public domain in our contemporary cities. Let's remember that when it is said 'this is the public space of the city' it is usually meant an official monumental space, which using Walter Benjamin's words is reserved for the celebration of the history of the victors. Cities usually cultivate memorials and historic landmarks that celebrate the memory of those who have succeeded at the expense of the forgotten memory of those others who have not. In so doing, cities often forget the nameless and vanquished, the victims, witnesses and 'survivors' of todays of yesterday's crimes and injustices.

Democracy, as Claude Lefort ${ }^{7}$ reminds us, is based on uncertainty and legitimized by the declaration of rights -the right to declare in public, among them- and by the presence of others. $^{8}$ Public Space, and by extension the democratic public space, is an assertive and affective space, a space for assertion of political and cultural rights and of public appearance. Hence, In considering the notion of the public sphere as the space of appearance we should question not only of how we appear but of how we respond to the appearance of others -those others that, as French philosopher Emmanuel Levinas reminds us, are not an object of comprehension but an enigma of a Face that resist possession, cannot be fully known and cannot be reduced to content. ${ }^{9}$ That is, at its core, a question of the ethics and politics of living together in a heterogeneous space. To be public and to be in public is to be exposed to alterity. 


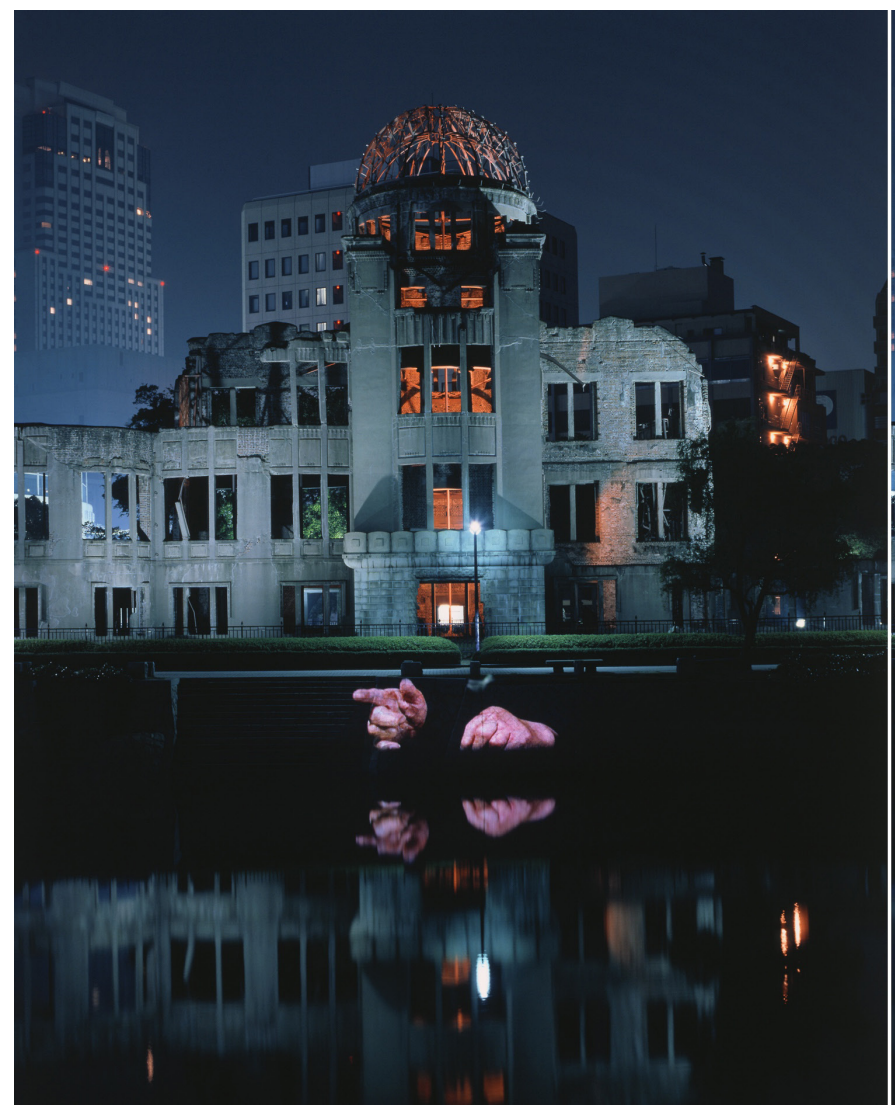

Figure 2: Hiroshima Projections - Krzysztof Wodizcko.

According to Hanna Arendt ${ }^{10}$, political equality means visibility; conversely, political inequality and invisibility go hand in hand. So, to a significant extent, the success of democracy and indeed of democratic public space can, and perhaps should be measured by its capacity to encourage and assist in the process disruption of the continuity of the history of the victors (and of the cities' symbolic narrative) by the tradition and memory of the vanquished and the nameless through political, cultural, spatial, and yes, architectural and artistic means. ${ }^{11}$ In this sense, we, as teachers, artists and architects who want to deepen and extend the public sphere have a twofold task: creating works that, one, help those who have been rendered invisible to "make their appearance explicitly" and, two, develop the viewers' capacity for public life by asking them to respond to, rather than react against, that appearance." My design partner (Wodiczko + Bonder) Kryztof Wodiczko's Hiroshima Projections, for instance, transformed the remains of the Hiroshima A-Bomb site, into a 'speaking and declaring monument'. Survivor's proactively declare in public and through their projected testimonies 'demand' from viewers to find ways to respond in and to the present. ${ }^{11}$ (figure 2)

\section{MEMORY-WORKS: THE WORKING MEMORIALS}

Engaging with the question of how history and histories, memories and traumas will be "appropriated," "re-presented,"

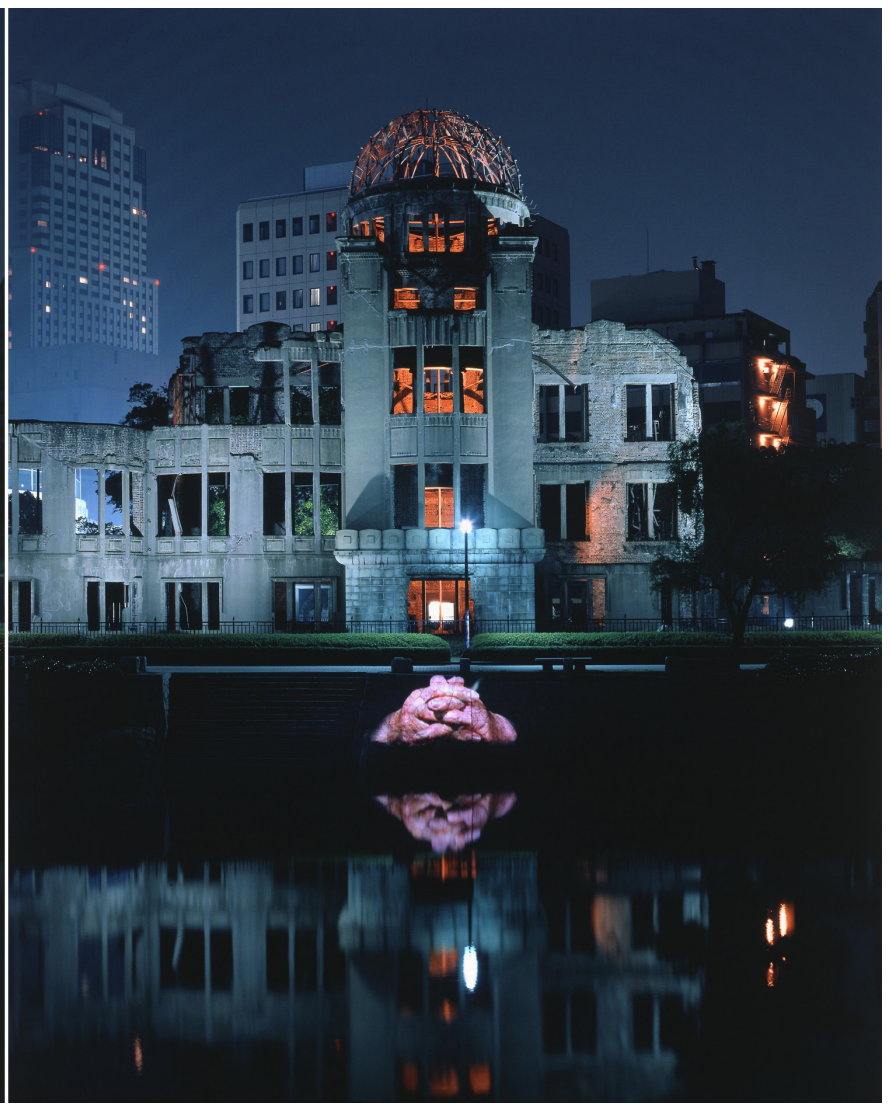

and "inhabited" and how will these be inscribed into the public domain and our built environment thus raises a whole host of issues that we should attempt to address: Can memorials work-through and shed light over difficult memories, past and present injustices, collective traumas, while inviting the public to engage in the necessary transformative, pedagogic, healing and re-constructive work? Can we envision site-specific memorials that will frame collective and spontaneous acts of remembrance, will demand pro-active engagement, and will contribute to envisioning a better world? Architecturally and artistically, can or should memorials attempt to engage new generations and visitors in the search for memory, through the absence of direct signs, or overt metaphorical representation? How can we welcome those others who address us from the deep wells of history and from the present wells of memory in our democratic societies? Can we make room for the voices of those others to "appear" in public without attempting to speak for them nor to represent their (our) trauma and pain? What about those who can speak, those who can bear witness, and those who cannot? What about those who don't have the "possibility" to appear, and those we painfully know will not "re-appear"?

I would like to suggest that working on such projects demands very precise, dialogic and committed attitudes towards design, towards techniques and materials, towards sites of memory, towards history, towards democracy, and especially towards the Faces and voices of others. It, thus, 


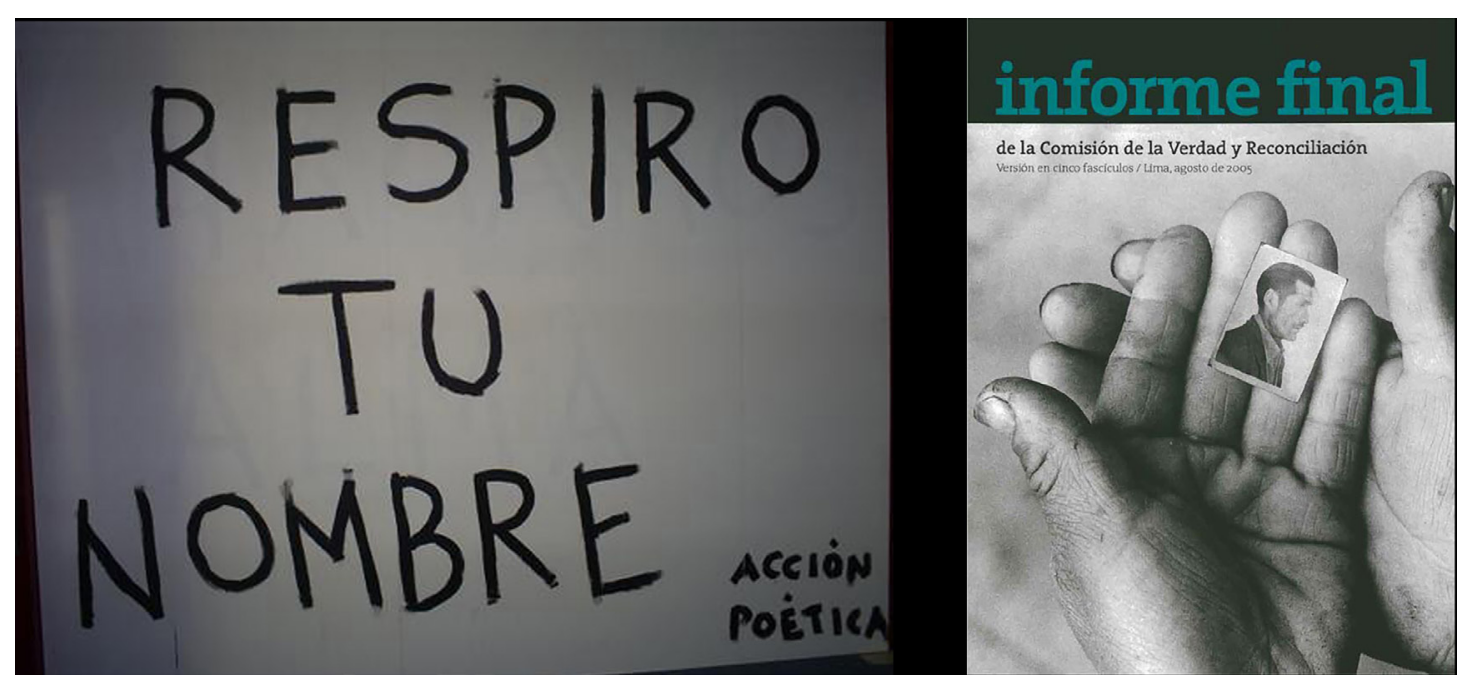

Figure 3: Comision de la Verdad y Reconciliación - Perú

involves establishing clear critical-ethical frameworks to position ourselves as profoundly engaged and committed witnesses. In this regard, I believe it would be important to follow philosophers, such as Giorgio Agamben, who have theorized the position of the witness as the basis of ethical and political relations insofar as the witness answers to the suffering of others without usurping the place of the other ${ }^{12}$. Witnessing is a way of seeing and listening that requires an acceptance of vulnerability. It requires a renunciation of the will to mastery. For, as trauma theorist Cathy Caruth argues ${ }^{13}$, to bear witness to the truth of suffering over a traumatic event is to bear witness to that event's incomprehensibility. This poses a problem for representations that want to respond to the suffering of others. While traumatic suffering calls out for the event to be witnessed, it creates a need for a new kind of witnessing-what Caruth calls the witnessing of an impossibility, the impossibility of comprehending the trauma. ${ }^{14}$

In this light, we need to be mindful and weary of the expectation of creating instant metaphors and artificial meanings. I think is important to constantly remind ourselves that neither art, nor architecture can (nor should these practices attempt

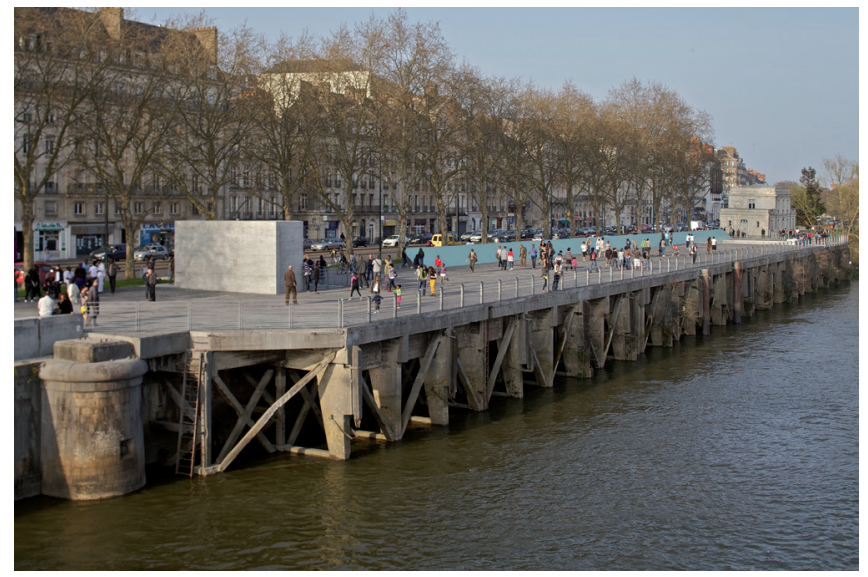

Figure 4: Memorial to the Abolition of Slavery - Nantes, France Design: Wodiczko + Bonder, Cambridge, MA Photo: Philippe Ruault to) compensate public trauma or mass murder. ${ }^{15}$ What architectural and artistic practices can do is establish a dialogical relation with those traumatic events and contribute to frame the complex and often difficult process toward understanding and, perhaps, only perhaps, healing.(figure 3)

Such issues and complex questions (often without answer) call out for a conscious and humble approach, which I would like to characterize as "ethical deferral." This approach involves inhabiting distance as one's place for action inhabiting the distance between act and remembrance, recollected worlds and worlds to be transformed. It entails asserting "presence" and "authorship" through a dynamic interaction and imbrication of conceptual and material worlds within (and without) the work, with the goal of ultimately effacing oneself and disappearing from the scene.

The thesis, the premise, of this approach is that memorials that work, Working Memorials, can foster and encourage new kinds of public engagement towards making the world a better place. By engaging various modes of perception, imagination and experience these projects should serve to re-inscribe sites into the cognitive maps of cities, and their cultural and physical landscapes. I would also argue that Memorials should attempt to create conditions for memory to be found within, in opposition to what can be called memory-objects, working "against the "tendency of displacement," 16 or the reduction of the viewer to passive spectator. I would also argue that in designing such projects we should attempt to illuminate 'presences' and 'absences' through materials beyond materiality, through language beyond representation, through art beyond art, through space beyond space. Their ethics, esthetics and politics should then articulate questioning, discursive, interrogative pedagogic, emotional, therapeutic and healing potentials. Shaped by an awareness of the need to address plurality of publics and generations, these Working Memorials, should become active agents for culture and dialogue, demanding 


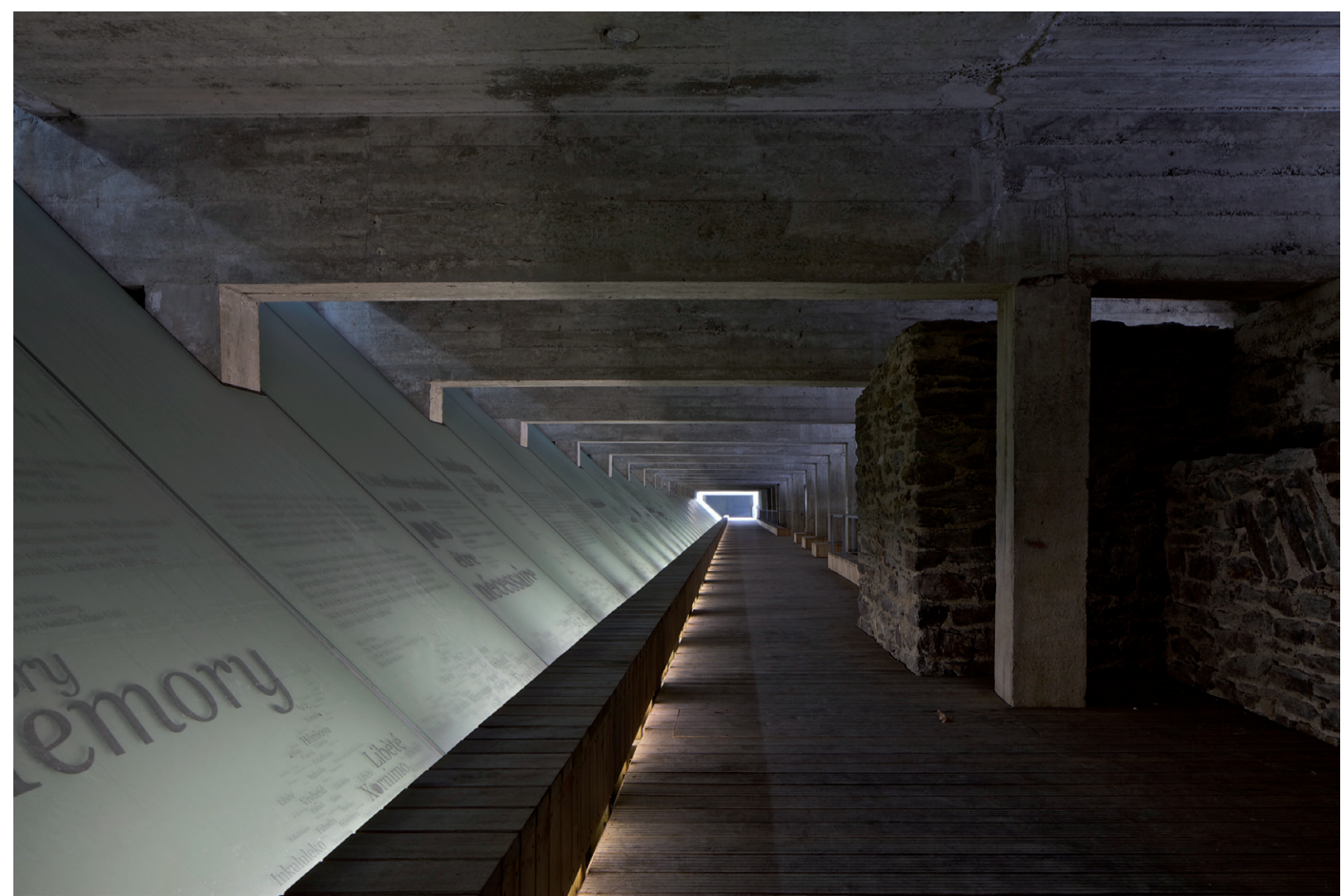

Figure 5: Memorial to the Abolition of Slavery - Nantes, France Design: Wodiczko + Bonder, Cambridge, MA Photo: Philippe Ruault

responsibility and eliciting "response-ability", human rights activism and civic engagement.

At the same time, I believe that upon conceiving and designing these projects (monuments, museums, memorials) we should be aware of significant risks, such as the objectivation of memory, the aesthetization of suffering or worse, its banalization. But these are risks that we should take, with care and respect, so that memory does not stay immersed inside but is affirmed in the public domain. Aesthetics should be at the service of ethics, and of life. As James Baldwin suggested:

"One must say Yes to life, and embrace it wherever it is found - and it is found in terrible places. ... For nothing is fixed, forever and forever, it is not fixed; the earth is always shifting, the light is always changing, the sea does not cease to grind down rock. Generations do not cease to be born, and we are responsible to them because we are the only witnesses they have. The sea rises, the light fails, lovers cling to each other and children cling to us. The moment we cease to hold each other, the moment we break faith with one another, the sea engulfs us and the light goes out ${ }^{177}$

This is the attitude I have tried to bring to my teaching ${ }^{18}$, to my design work ${ }^{19}$-which includes our project for the Memorial to the abolition of Slavery in Nantes (figure $4 \& 5$ )- and to multiple endeavors and collaborations across disciplines. ${ }^{20}$ This approach involves understanding art, architecture, and landscape as mediums capable of shedding light over a limited set of truths and values in a space located between the questions, the publics, and the instruments of our practices.
It involves attempting to contribute to the construction of a "democratic" and "agonistic" society, as authors, designers, architects, engaged witnesses and sentient subjects, through an ethics of deference to the "other" - that is, "moving out of ourselves" $\neg$ following Levinas- when proposing transformative actions in the public domain.

\section{A FINAL (QUITE UNFINISHED) NOTE}

Through my multiple practices and teaching, I am interested in suggesting, first, an approach to memory and memorialization in public space, that understands memory as an action, memory as a 'verb', rather than an object or a noun. Second, I also think we should attempt to broaden the understanding and sense of the word 'memory', corseted in the last few years in discussions about public space to mean almost exclusively evoking traumatic histories and events (this is quite an unfinished point to be further amplified and elaborated). Third, I want to reimagine the practice and teaching of architecture, design and art in relation to history and memory, with a renovated sense of agency and public purpose. And, last but not least, I would want to further discussions and investigations across disciplines that would address, and perhaps chart new approaches to cultural sustainability and democratic public domain.

\section{ENDNOTES}

1 Andreas Huyssen, "Introduction," in Present Pasts: Urban Palimpsests and the Politics of Memory (Stanford: Stanford University Press, 2003).

2 Emmanuel Levinas, Difficult Freedom: Essays on Judaism, Seán Hand, trans. (Baltimore: Johns Hopkins University Press, 1997).

3 See Andreas Huyssen, Introduction to Present Pasts, Urban Palimpsests and the Politics of Memory, (Stanford University Press, 2003).

4 Andreas Huyssen suggests that "national memory debates are always shot through with the effects of global media and their focus on themes such as genocide and ethnic cleansing, migration and minority rights, victimization and accountability. 
However different and site-specific these causes may be, this does suggest that globalization and the strong reassessment of the respective national, regional, or local past will have to be thought together". See Andreas Huyssen, Introduction to Present Pasts, Urban Palimpsests and the Politics of Memory, (Stanford University Press, 2003).

5 I have been as designer, architect and teacher an active contributor to contemporary national and international debates on memory, public space, public art, cultural trauma and design. My design work includes projects for museums, memorials and public spaces dealing with Holocaust memory, the Civil War, Civil Rights, Slavery, the Desaparecidos, as well as September 11. Having designed through our Cambridge-based partnership, Wodiczko +Bonder the Memorial to the Abolition of Slavery in Nantes, among many other projects, this short essay attempts examine how memory and memories work, and how they are manifested in the built environment.

6 See James Young, The Texture of Memory (New Haven: Yale University press, 1993), 12

7 For Claude Lefort, the hallmark of democracy is uncertainty about the foundations of social life. "Democracy," says Lefort, "is instituted and sustained by the dissolution of the markers of certainty. It inaugurates a history in which people experience a fundamental indeterminacy as to the basis of power, law and knowledge, and as to the basis of relations between self and other." He ties the ability to appear to the declaration of rights, that is to declare, to speak in the public sphere. See Claude, Lefort. The Question of Democracy. Democracy and Political Theory. (Minneapolis: University of Minnesota Press, 1988), 19.

8 Describing the Other as that which approaches but cannot be reduced to a content, Levinas distinguishes what appears from what is fully seen. What is more, when the other appears, he is accompanied by something else, something Levinas calls "the third party," whose "apparition," he says, is "the very origin of appearing." See Emmanuel Levinas, Otherwise than Being, or Beyond Essence, trans. Alphonso Lingis, (Pittsburgh, Duquesne University Press, 1981) 160.

9 See Colin Davis, Levinas: An Introduction, Notre Dame, University of Notre Dame Press, 1996, 83

10 For a thorough and compelling discussion on Hanna Arendt and Public Space / Public Life see George Baird "The Space of Appearance" - MIT Press, 1995

11 Examples include endeavors that seek reparative justice and symbolic justice, marches and public demonstrations, organizations that fight against presentday forms of slavery, mass incarceration and other forms of oppression, Truth and Reconciliation Commissions, the removal of monuments from Public Space, and many more. Other examples include artists and collective groups that contribute with their works to make visibly visible the nameless and the vanquished such as Alfredo Jaar, Cindy Sherman, Barbara Kruger, Marcelo Brodsky, Grupo Arte Callejero, Accion Poetica, Jenny Holzer, Priscilla Monge, Benvenuto Chavajay, Chto Delat, Muntadas, Krysztof Wodiczko, among many others. Much of our collaborative work at Wodiczko+Bonder is based on these issues and questions.

12 See Giorgio Agamben, Remnants of Auschwitz: The Witness and the Archive (New York: Zone Books, 1999).

13 Cathy Caruth, "Recapturing the Past: Introduction," in Trauma: Explorations in Memory (Baltimore: Johns Hopkins University Press, 1995).

14 In Unclaimed Experience, Cathy Caruth suggests that Trauma can be experienced in at least two ways: as a memory that one cannot integrate into one's own experience, and as a catastrophic knowledge that one cannot communicate to others. Since by definition the event that caused psychic trauma-a wound inflicted on the mind-was so overwhelming that it could not be fully known or experienced at the time, the victim suffers from incomprehension, and this means that for the witness to claim to know the experience is to understand too much and therefore to betray the victim. See Cathy Caruth, "Recapturing the Past: Introduction," in Unclaimed Experience, Baltimore and London, The Johns Hopkins University Press, 1995.

15 Often, and especially in the wake of catastrophe, a "redemptive aesthetic" emerges in the affected communities alongside public acts of commemoration. The redemptive aesthetic asks us to consider art (or architecture) as a correction of life. Leo Bersani writes "The catastrophes of history [appear to] matter much less if they are somehow compensated for in art", from Sidra DeKoven Ezrahi in Booking Passage, Exile and Homecoming in the Jewish Modern Imagination, (Berkeley: U. of California Press, 2000), 144.

16 As Young writes: "to the extent that we encourage our monuments to do our memory-work for us, we become much more forgetful". See James Young The Texture of Memory (New Haven: Yale University press, 1993), 5.

17 From The Fire Next Time (1963), as quoted by Henry Giroux in an Open Editoria entitled "Why Don't Americans Care About Democracy at Home?" at Truthout at 2012-10-02.

18 For example: various seminars on public space and public art and studios such as WTC, Vietnam Memorial Information Center, New York Holocaust Museum, Temporary September 11 installations in Syracuse \& Nebraska, and the series "Unearthing the Traces of to Rhode Island's Slavery and Slave Trade" design studios which included projects in Newport, Bristol and Providence, and received 2016 ACSA Creative Achievement Award.
19 Examples include collaborative projects through our firm Wodiczko + Bonder for Hoboken September 11 Memorial, Memorial to the Abolition of Slavery in Nantes, France, Babi Yar Park, Denver, Canada Holocaust Monument, as well as design work for Center for Holocaust Studies, Clark University, Buenos Aires Holocaust Museum, Puchavichi Memorial and proposals in Latin America.

20 Conversations across disciplines include: Democratic Memorial: Public Policies of Memory, Barcelona, Keynote Address at the 4th Annual International Human Rights Conference, Pontificia Unversidad Católica del Perú in Lima; work and membership at EUROM (European Observatory of Memories) and member of the advisory board to the Symbolic Reparations Research Project (Latin America), speaker at "Universities and Slavery: Bound by History" at Radcliffe Institute, as well as speaker at Conference: Slavery and the Universities, Emory University, and others. 